\title{
Uniting nursing theory and current practice to manage suicide in Canada
}

\author{
Kimberly Ann Jones * \\ St. Joseph's Healthcare, Hamilton, Ontario, Canada
}

Received: December 17, 2015

Accepted: April 10, 2016

Online Published: May 10, 2016

DOI: $10.5430 /$ jnep.v6n9p73

URL: http://dx.doi.org/10.5430/jnep.v6n9p73

\begin{abstract}
During the last thirty years, more than 100,000 Canadians have died by suicide, remaining one of Canada's critical public health concerns. According to the World Health Organization there is one suicide every forty seconds worldwide, an increase of $60 \%$ since 1950 . Suicide is the single greatest source of violent deaths internationally, generating more deaths per annum than casualties of war and homicides combined. Twenty-five years ago, Canada's National Task Force on Suicide investigated the suicide phenomenon and created its first report in pursuance of the development of better policies. The exploration for suicide risk factors (variables that denote an increased probability for suicide) has been embarked on by a variety of researchers and clinicians, but Canada's suicide rate still exceeds the average in comparison to other countries. Although this Canadian public health crisis persists and escalates each year, it is a preventable concern that requires a new methodology. The purpose of this journal article is to explore and examine ethical issues surrounding the suicide epidemic in Canada. It will review the changes in Canada's prevention and treatment of suicidality during the last few decades and the challenges that nurses currently face when treating suicidal patients. Additionally, it suggests that suicide may be better managed by utilizing the Collaborative Assessment and Management of Suicide (CAMS) framework combined with the Human Becoming Theory as a foundation for the nurse clinician; and that qualitative contribution to the treatment of suicide is paramount. It examines the CAMS framework in more detail, particularly how if differs from other counseling approaches and reinforces the therapeutic alliance between client and therapist. This article encourages health care providers to re-evaluate their current suicide risk assessments by not only reviewing nursing theory, but implementing formalized suicide tools. Although this article frequently makes reference to the nursing profession, it is intended to broaden interest in CAMS for a variety of health care specialists in the mental health arena. Therefore, the terms' nurse and health care professional are used interchangeably throughout to address a larger audience.
\end{abstract}

Key Words: Suicide, Collaborative assessment and management of suicide, Parse, Suicide in Canada, Human becoming theory and nursing

\section{Literature REVIEW}

For this article, an extensive literature review of 50 peer reviewed journal articles was performed using the snowball method in English language articles in Ovid, CINAHL and Medline, from 2000-2015. Key words such as CAMS, suicide, nursing theory, Parse, and Human Becoming Theory were used.

\section{Past practice in Canada}

Canada's multiplicity and inclusiveness distinguishes it from a majority of other countries, with its thirty-four million citizens signifying a cultural, ethnical and etymological character found nowhere else on this globe. ${ }^{[1]}$ Canada's continued immigration and stratagems on multiculturalism has resulted in a shifting Canadian topography. Currently, there

\footnotetext{
* Correspondence: Kimberly Ann Jones, RN, BScN, MNursing, CPMHN (c); Email: jonesk@ @tjoes.ca; Address: St. Joseph's Healthcare, Hamilton, Ontario, Canada.
}

Published by Sciedu Press 
are over two hundred ethnicities represented across Canada, contributing to a vast blend of ethnic, linguistic, and spiritual diversities. ${ }^{[2]}$ With diversity, however, comes an array of societal health alarms such as suicide. Understanding suicide precursors in a country as ethnically diverse as Canada is essential in order to facilitate the development of suicide deterrence strategies. ${ }^{[3]}$

Canada is well known for its long history of prevention efforts on a variety of public health concerns, however; suicide is not one of them. Similar to other countries, past practice in Canadian mental health has utilized humanitarian, institutionalization and deinstitutionalization approaches. ${ }^{[4]}$ Until 1972, suicide was considered a crime in Canada with stern sanctions and punishments imposed, not only on those who attempted suicide, but on their families as well. The crime of suicide was collated in Canada with the establishment of the Criminal Code in 1892 but it was removed in 1972 by the Parliament of Canada, based on the contention that lawful deterrents were excessive.

The expression "suicidal behaviour" includes completed suicide (death by suicide), attempted suicide (intended selfinflicted harm) and suicidal ideation (thoughts of suicide). ${ }^{[5]}$ Prior to 1981, there were no programs for suicide prevention in Canada. The Canadian Government began to identify suicide as a major problem in the 1970's after a study commissioned by Marc LaLonde, the Minister of Health, identified it as a chief cause of premature death. ${ }^{[6]}$ Recognizing this as imperative, Health and Welfare Canada met in 1980 and established the National Task Force on Suicide, and generated their first public statement, Suicide in Canada: Report of the National Task Force on Suicide in Canada 1987. This comprehensive synopsis detailed the sheer size of the suicide crisis and examined the epidemiological and etiological knowledge base, and presented findings on particularly high-risk populations and provided recommendations on prevention, intervention, and postvention measures. ${ }^{[7]}$

The focus of the recommendations included expansion of research on suicide, particularly in the youth population, the launch of a capacious, countrywide mortality registry, evaluation of existing data collection measures to homogenize methods and augment efficacy, and the examination of current training in suicide prevention. While several of the recommendations ignited some accomplishments, on the whole very little has been done in response to these suggestions, even decades later. A restructured adaptation of the report was created in 1994, and many of the original proposals were recapitulated.

In various regions of Canada, provincial programs focused on nationally recognized components of suicide but with no official provincial policies and with little funding designated for prevention programs and research. One success however, was the development of volunteer based 24-hour crisis lines. These telephone based crisis response services now exist in most major cities across Canada.

In 1995, a Royal Commission was created to explore the crisis of suicide among Canadian Aboriginals. After nearly two hundred days of public hearings in almost one hundred communities across the nation, the Royal Commission summarized their findings. ${ }^{[8]}$ The report featured various hopeful methodologies that were being initiated by Aboriginal groups but also indicated potential barriers to success as well. It suggested that attention to community ideologies is greatly needed.

In 2004, the Canadian Association for Suicide Prevention (CASP) published Canada's first national suicide prevention stratagem that called for the Canadian Government to take a primary role in applying its Healthy Living Strategies, while implementing the recommendations indicated in their report. ${ }^{[9]}$

Despite the call for more research into prevention programs, knowledge in this area continues to be limited. ${ }^{[10]}$ Recently, there have been some innovative initiatives on suicide across Canada that have inspired research and empirical data, but only a small number of those have been produced by women, racial minorities, or Aboriginal people. ${ }^{[1]}$ What's more, investigations about suicide from a nursing or social work perspective remain uncommon, regardless of the significance of suicide prevention to these occupations. ${ }^{[8]}$ Regrettably, treatment modalities for suicidal persons and the bereavement of their families have not received much consideration by Canadian researchers.

Very few Canadian studies have explicitly analysed the efficacy of education in suicide prevention and intervention, despite the fact that training of healthcare professionals comprises a critical necessity of suicide prevention efforts. ${ }^{[12]}$ It would appear that in the thirty-year history of suicide prevention planning in Canada, there have been some small successes but much work remains to be done.

\section{NURSING THEORY AND CLINICAL PRAC- TICE}

Nurses working in today's ever-changing mental health care milieu, are becoming increasingly conscious of the need to evaluate and advance their practice while considering the political, social and structural concerns affecting it. ${ }^{[13]}$ The harmony between theory, research and practice continues to be essential for the advancement of mental health nursing. The past century has observed many impressive changes to 
the nursing profession. During the twentieth century, nurses promoted nursing theory as its primary knowledge base that guided clinical practice. The improvement and refinement of patient care and the promotion of nursing as a profession versus occupation has been paramount. ${ }^{[14]}$ Nursing theory has expanded to include numerous levels of conjecture, and has become a scholarly tête-à-tête amongst various theorists. ${ }^{[15]}$

Historically, empirical data has represented truth and knowledge. However, as of late, these established scientific methods are not always appropriate for creating knowledge required for the benevolence of nursing, particularly in mental health. ${ }^{[16]}$ Like nursing, many social and behavioral sciences are contingent on other methods to establish knowledge. Nursing relies on multiple approaches to gain its wisdom, and it embraces characteristics of social, behavioral and biological sciences. There remains an emphasis on the progression of nursing knowledge through research and theory building to improve clinical practice. Given the suicide statistics in Canada, this ought to drive clinical nursing as well. It is implicit that theory-guided practices maintain the vision of psychiatric and medical nursing, while integrating applicable, outcome-driven performance actions, skill, caring and science that is seen in holistic underpinnings. ${ }^{[17]}$

The intricacies of nursing often elicit a robust discussion about the connection between theory and practice. ${ }^{[18]}$ In this debate, there is often a dissection between what is experienced in actuality and what is taught in the clinical setting, and is often referred to as a theory-practice gap. ${ }^{[19]}$ Nurses generate informal theory out of practice, and then apply that theory back into practice, and adjust the theory as a result of the revised clinical setting. ${ }^{[20]}$ Hence, theory and practice are two parts of the same process, and the theory-practice gap ought to be resolved. Nursing continues to search for knowledge that gives theoretical sustenance to its practice.

Nurses enhance patient care through nursing theory; they apply real life familiarity, knowledge and cognitive reasoning that extend beyond the scientific methodology of empirical knowledge. ${ }^{[21]}$ Scholars argue that the gap between theory and practice is mostly due to the failure of nursing theory to satisfactorily account for what happens in real life. ${ }^{[19]}$ The "art of knowing" in nursing theory transformed practical nursing from its heavy reliance on empirical presumption to include a reflective practice that is supported by the nurse's and patients' lived experiences. ${ }^{[20]}$

To ease the recognition of nursing knowledge, a framework that reflects the nature of daily nursing of the patient with suicidal ideation and intent is essential. It is in this concept that knowledge materializes from actions and clinical experiences. Therefore, empirical based knowledge does not always provide answers to nurses nor guarantees best clinical practice. Nursing must utilize various types of knowledge, such as practical, personal and experiential. ${ }^{[22]}$ Consequently, bringing conventional theory to current-day frameworks is a valuable tool to decrease suicide in Canada. It can improve nurses' approaches to suicide; and increase their confidence and core competencies; it helps guide assessment, intervention, and evaluation of nursing care. Theory is what makes nursing a profession. It provides direction and guidance for shaping clinical practice, education, and research and cultivates independence in the nurse while setting standards and criteria to measure the quality of clinical competency.

\section{ETHical CHALlENGES IN NURSING THE SUICIDAL PATIENT}

Pompili states that suicide is the end result for those experiencing unbearable, psychological pain and suffering, who believe that ending one's life is the best solution. ${ }^{[23]}$ Likewise, Pompili emphasizes that stigma must be replaced by meaningful phenomenology, where the healthcare provider wholeheartedly understands the suicidal person's intimate world, their unique, individual misery, their suicidality as a phenomenon centered in them.

Many therapies have been successful in reducing symptoms of psychiatric illness, but few have been found valuable in reducing suicidal behaviour. ${ }^{[24]}$ Since there are no current standards of care for the prediction of suicide; risk assessment must be an essential core skill for medical personnel.

A literature review performed in 2001 by Vicki May on professional attitudes revealed that staff had a propensity to show 'unfavorable' attitudes towards patients exhibiting suicidal behaviours. ${ }^{[25]}$ Soukas and Lonnqvist (1989) compared approaches to suicidal behaviour amongst emergency and ICU staff, noting that attitudes were more negative among the emergency staff. ${ }^{[26]}$ Rhodes' 2003 annotation on John Cutcliffe: A Historical Overview of Psychiatric/Mental Health Nursing Education, indicated that even at the academic level, there is a limit as to how much a nursing student can learn in nursing programmes, and that empathy and the foundation of therapeutic relationships is lacking in current nursing curriculum. ${ }^{[27]}$ In Valente's 2011 study that analyzed 454 oncology nurses' attitudes and knowledge of suicide, she stated that suicide remains a serious sentinel event and that nurses are central in evaluating risk and preventing death. She suggested that psychological factors such as emotions, unresolved grief, communication and negative judgments about suicide complicate the nurse's assessment and treatment of suicidal patients. ${ }^{[28]}$

Simon stressed that "suicide risk assessment is a process, not 
an event". [29] Nursing assessments are considered critical in the treatment of suicidal patients. ${ }^{[30]}$ Suicide assessments should include an individualized evaluation of a patient's overall risk as soon as the patient exhibits a need for treatment. Although clients may express suicidal ideation openly with statements such as "I am planning on ending my life", there may be inferred remarks such as "I feel hopeless about my future". Overt behaviours such as giving away belongings, or socially isolating oneself from family, friends and community should be considered serious. In one inpatient study, results showed that clinical assessments failed onequarter of the time in documenting history of suicidal behaviours by patients with previous attempts. ${ }^{[31]}$

In emergency departments, patients with suicidal ideation receive an evaluation, and interventions and treatment plans are then discussed and the patient receives a disposition of either discharge or admission. Lizardi and Stanley completed a literature search on patient adherence post-discharge, and on follow-up treatment from the emergency department. ${ }^{\text {[32] }}$ They reviewed a number of studies that examined interventions to increase compliance. What they found was that clients who work collaboratively with a therapist had an improvement in their condition, and urgent follow-up after discharge helped motivate the client to attend appointments. Their statistics were startling, that suicide attempters are difficult to engage in treatment: $11 \%-50 \%$ decline outpatient treatment or withdraw quickly, up to $60 \%$ do not attend more than one week of treatment and $33 \%$ are no longer in treatment at the three-month mark. Further results indicated that follow-up contact must be substantial to be efficient, as these patients are at high risk to suicide during this three-month period following discharge. ${ }^{[33]}$ Lizardi and Stanley questioned why suicide attempts and death by suicide continue to escalate in Canada in spite of the changing distribution in sex, race, age and ethnicity, and the increased awareness and heightened prevention measures. What's more, while inpatient admission has been the standard of care, it has never been found efficacious in clinical trials. ${ }^{[34]}$

\section{Collaborative aSSESSMENT AND MAN- AGEMENT OF SUICIDALITY - HOW IT VARIES FROM TRADITIONAL COUNSELING}

Traditionally, the Medical Model for suicide focused on those conditions thought to be behind the suicidality, i.e. major psychiatric illness (Depression, Bipolar Disorder or Schizophrenia) or substance abuse. ${ }^{[35]}$ It assumed that suicidality would resolve as diagnoses were treated. Furthermore, its approach was that the clinicians are the experts who focus on the primary diagnosis, and it is they who develop the care-plan for the patient. However, current data asserts that targeting the person's suicidal ideation diametrically is more progressive at decreasing the suicidal thoughts and behaviours than such outdated models. $^{[36]}$

Contemporary treatment of the suicidal patient can elicit struggles and risks for front-line staff. Irritation, despondency, fear and hopelessness are some of the feelings evoked in clinicians working with this population. Jobes lists a variety of concerns lingering in traditional clinical practice. These include ineffective assessment skills, dubious customs such as persistent, coercive 'no-harm' contracts, brief or lengthy inpatient admissions and an over-confidence in medication-only approaches. ${ }^{[37]} \mathrm{He}$ further adds that most clinical personnel do not assess suicidality which leads to poor clinical documentation, nor employ evidence-based interventions.

Past treatments have been inadequate in speaking to the significant burdens and needs of patients experiencing suicidal ideation. In previous practices, clinicians rarely used suicide-specific risk assessment tools and favoured inpatient admissions as treatment for suicide. Once admitted, patients received rigorous group and individual therapy and behaviour activation undertakings, and were prescribed medications such as first-generation anti-depressants. ${ }^{[38]}$ Besides, using medications to treat suicidal symptoms does not ensure that clients will indeed take them. Even those with low passive suicidality were routinely hospitalized with lengthy admissions for medical stabilization and close observation. Safety contracts coerced patients to sign a written form affirming that they will not end their lives. Although still used, they provide no protection against litigation should a client end his life. Instead, they shame clients into signing something that is not legally contractual.

Given the value in unravelling suicidality and lessening the nervousness experienced by nurses and healthcare professionals, there is an obvious call for ground-breaking services and new methodologies in Canada. ${ }^{[39]}$ David Jobes created the Collaborative Assessment and Management of Suicidality framework (CAMS) which functions as a way of not only assessing suicide risk, but acts as a foundation for the development of the therapeutic alliance that is considered vital when working with patients who have little incentive for accepting help. ${ }^{[40]}$ His approach is a therapeutic model that modifies how care providers currently connect with, assess and treat the suicidal individual. ${ }^{[36]}$

CAMS is a clinical paradigm that features collaboration between therapist and client, and compassion for the suicidal mind. It assumes that suicidality is a maladaptive coping strategy but an option to emotional pain. It increases motivation in the patient in a joint effort to effectively target and 
treat the patient's suicidal risk. The therapeutic alliance coupled with improved patient motivation leads to good clinical outcomes for the highly suicidal client. ${ }^{[41]}$

CAMS has advanced considerably over 25 years, with numerous published open trials and correlational investigations and randomized clinical experiments, displaying its success in an assortment of outpatient milieus. ${ }^{[42]}$ Different from other treatment modalities, the CAMS framework allows the clinician and patient to liaise and develop a collective sense of their suicidality while considering overall risk for self-harm. Outpatient treatment is the goal of the CAMS clinician, a different approach than conventional thinking which preferred inpatient care for the suicidal patient. ${ }^{[43]}$ Although the clinician and client participate in the assessment process together, it is the client that is encouraged to cultivate their own treatment plan and urged to provide feedback at each session about what is successful or not. In the past, it was the therapist that told the client why they felt suicidal, however, the teamwork of CAMS urges the client to tell the therapist why, allowing him to be the expert of his own treatment plan. ${ }^{[4]}$ The nurse or therapist utilizes a benevolent and non-judgmental approach to understand each client's suicide perspective.

CAMS is guided by a seven page clinical tool called the "Suicide Status Form" (SSF), which funnels the patient's treatment. This form considers a number of suicide drivers such as psychological pain, stress, agitation, hopelessness and self-hate through the use of a Likert Scale. The SSF has evolved into a multipurpose, clinical assessment and treatment tool that uniquely assesses both quantitative and qualitative aspects of the suicide threat. ${ }^{[45]}$ It is seen as a psychometrically valid and reliable instrument for suicide assessment, offering a brief and consequential method of clinically understanding one's suicide drivers and risks. ${ }^{[38]}$ The SSF allows the clinician to document assessments and treatment-plans that are specific to suicidal thoughts and behaviours. Furthermore, it monitors ongoing risk and clinical outcomes in real-time.

Each CAMS session allows the clinician and client to identify those drivers that lead to suicidal ideation. Suicide plans and access to means are discussed, as are crisis response and treatment strategies. The length of CAMS depends on how long it takes for suicidality to resolve. Typically, sessions occur in one hour weekly appointments, ranging from a minimum of four sessions to an average of twelve. Clients respond well when identifying, targeting and treating their drivers with problem-focused interventions that increase their motivation to live, and suicide is considered resolved when death is no longer the answer. ${ }^{[39]}$
The first CAMS session assesses overall risk after a patient has reported current suicidal ideation or ideation over the last seven days. The clinician asks to sit directly beside the client to facilitate collaboration. The client is oriented to the CAMS process and the clinician asks what the suicide means to him. The client is asked provocative questions such as 'what is the one thing that would make you want to live' or 'why have you chosen suicide as a way to end your suffering?' Suicidal thoughts are identified and addressed within the first ten minutes of interaction; the nurse encourages the client to list reasons for dying and reasons for living. The client is asked to commit to the time-limited, suicide-specific treatment plan, in other words, to stay alive and proceed with the therapist.

The use of a crisis response plan is a newer technique, different than the previous no-suicide contracts. The client develops his own safety plan should he become acutely suicidal, impulsive or depressed. The creation and use of the crisis card encourages clients to connect with significant others, and encompasses behavioural activation, such as calling a friend, journaling, reading, walking, or meditating. The client can keep the crisis card in a pocket or wallet, where it is easily accessible. The goal is for the client to learn how to cope with crisis states in adaptive ways that will not end with suicide. ${ }^{[38]}$ It is always essential that access to lethal means be removed. At all successive appointments, the patient completes his own SSF assessment and re-examines his treatment plan, reviewing his progress and tackling emergent suicidal issues that need to be treated. Once there are three consecutive sessions of no suicidal thoughts, feelings, and behaviors, suicide is considered resolved.

\section{Parse, Phenomenology and CAMS: SIMILARITIES IN THINKING AND THEORY}

Nursing theorist Rosemary Parse created a theory supported in human sciences through an amalgam of concepts derived by Martha Rogers and from existential-phenomenological thought. Her intention was to improve nursing knowledge and the clinical experience for the betterment of the patient by replacing traditional theories of nursing. ${ }^{[46]}$ It conceived that the patient's perception of their quality of life should be the framework to guide nursing practice. It suggested that humans are a combination of biological, psychological, sociological and spiritual factors and are solitary persons that interact with their environment. ${ }^{[47]}$

Parse's Human Becoming paradigm emphasizes that it is the client who chooses and assumes responsibility for their own health, and the goal of the clinician is to see it through their perspective. The patient is the expert of his well-being and 
the nurse addresses his emotional, physical, spiritual and psychological needs. Integrative nursing is a science and art, a vocation of invention and creativity. ${ }^{[48]}$

Parse hypothesized that a nursing theoretical outlook should focus on the quality of life from the person's viewpoint, claiming that scientific, problem-based, investigative customs have failed to deliver the direction for fulfilling nursing's ethical directives to respect humanity. ${ }^{[49]}$ Traditional, standardized nursing interventions propagate a haunting disregard for human dignity. This lends increased credibility to CAMS which allows the quality of the patient's life to unfold distinctively, and with present-day health care practices that respect and revere human choices. Although CAMS is nontheoretical, its clinical approach to suicidal risk is similar to Parse's nursing theory. It attempts to understand the suicidal patient's uniqueness from their perspective. It provides direction for nursing practice and research because it targets the understanding of the subjective human experience while acknowledging personal liberty.

Phenomenology is a comprehensive discipline and research method used in philosophy and the human sciences. Its fundamental objective is to describe people's experiences, endeavoring to understand how people perceive phenomena and their meanings. ${ }^{[50]}$ A phenomenological research study is one that strives to comprehend people's perceptions and perspectives of their lived experiences, and investigates how people construct meaning.

Both the CAMS framework and Parse' theory emphasize the intricacy of the multidimensional human being within an equally diverse environment, utilizing phenomenological, qualitative methodologies in their research. Although the human experience cannot always be quantified, CAMS stimulates solutions to research questions about the lived experiences of the suicidal patient through phenomenology, necessitating the use of qualitative methods, while allowing for the identification of research gaps. Parse's efforts are also based on phenomenology which is of noteworthy importance to nurses engaged in qualitative research, particularly those working in mental health. ${ }^{[49]}$ Both CAMS and Parse's Human Becoming Theory form a foundation for holistic nursing that is much needed in working with the suicidal patient.

Nurses can apply Parse's theory to CAMS by honouring the suicidal patient's values and respecting their freedom to make choices about their health. This permits the patient to talk about his hopes, plans and concerns in an open forum that is not stigmatizing. The CAMS approach is an adjunct to both the Human Becoming Theory and medical science. Like theory and practice, CAMS, the Human Becoming Theory and medical interventions can work concurrently. Both
CAMS and Parse's theory suggest that fewer errors transpire when patients are actually listened to, thus leading to fewer complaints from patients and families and more pleasure and veneration in nursing work.

\section{DISCUSSION}

Suicide is a heartrending and painful experience. Its adverse effects on society, families and friends, fortifies the urgency for a better comprehension of its roots and its prevention. It is important to mention that deaths by suicide mirror only a small fraction of actual attempts, as it is estimated that for every one completed suicide, there are roughly twenty attempts. ${ }^{[51]}$ For these reasons, suicide risk assessment has been identified in Canada, and internationally, as a fundamental safety issue among health care organizations.

There are many clinical situations where healthcare providers need to perform a suicide assessment. Identifying and treating suicide necessitates a remarkable degree of perseverance, intuition, kindness, and ingenuity. What's important is that the care provider has access to theory and standardized frameworks to steer through it. Suicide risk assessments should be viewed as a fundamental part of the holistic, therapeutic practice, generating opportunities for discussion between the client, nurse, family and significant others. The Collaborative Assessment and Management of Suicide has withstood years of clinical research. It is an alternative to traditional biomedical and psychosocial methodologies. It guides assessment, treatment and tracking of suicidal risk and is a vital appendage for any clinician. Its phenomenological interview has a clear function, a means for exploring and assembling narratives of lived experiences. ${ }^{[52]}$ It is a medium to develop a conversational connection about the meaning of the patient's suicidal experience.

Bringing nursing theory to the care of the suicidal patient is also imperative in their management. The Human Becoming Theory bases its conjectural underpinnings in an inductive, qualitative approach, allowing the nurse to help suicidal patients find meaning in their anguish. Increasing patient acuity and the complexity of mental health care requires distinguished critical thinking skills with nursing theory substructures.

The Human Becoming Paradigm and the Collaborative Assessment and Management of Suicide framework allow for a broad, qualitative theoretical viewpoint. Both are adequately comprehensive to support multiple research methodologies and applications to clinical practice. Confronting suicide is a frightening thought for most nurses and healthcare providers, but having the theory and means to assess risk, and the ability to implement interventions and evaluate outcomes is elemen- 
tal for the healthcare provider's clinical tool belt.

Comtois et al. suggested that patients reduce their suicidal ideation in significantly fewer sessions, have fewer ER visits and primary care medical appointments when working with CAMS clinicians. ${ }^{[39]}$ In another pilot study on CAMS, Ellis et al. found that statistically and clinically, there were significant reductions in depression, hopelessness, suicidal ideation, psychological pain and self-hate in an inpatient sample group. ${ }^{[53]}$ Moreover, given the criticality of collaboration in the CAMS framework is the reinforcement of the therapeutic alliance during treatment, where health care providers effectively partner with patients on issues of suicide and safety.

In October 2011, Canada's House of Commons passed a nonpartisan motion in support of a national suicide prevention strategy, stating that suicide is a serious public health issue and public policy priority. They urged the government to work cooperatively with the provinces and territories to establish and subsidize a national suicide prevention strategy, and encouraged a comprehensive and empirically based methodology to manage Canada's suicide crisis. ${ }^{[54]}$ Although some progress has been made over the last 20 years, the approach to mental health requires adequate public support and government funding to ensure that Canadians obtain a comparable quality of service as they do when they receive treatment for other disorders. ${ }^{[5]}$

\section{Conclusion}

Suicide is a sudden end to one's life and the most extreme way in which people respond to overwhelming distress. It is a significant public health crisis not only in Canada, but remains a leading cause of death worldwide. Suicide is difficult to prognosticate and even harder to stop and there are barriers to studying suicidal thoughts and behaviours when utilizing previous and present-day assessment methods.

Jobes' Collaborative Assessment and Management of Suicidality steers clinical assessment and treatment by exhibiting a comprehensive illustration of one's suicidal thoughts and behaviours. His framework is intended to nurture the therapeutic relationship and increase one's enthusiasm to live by finding purpose and meaning. Like motivational interviewing, CAMS utilizes a laissez-faire curiosity and the therapeutic alliance to explore one's feelings and pain so that treatment goals are reached. ${ }^{[55]}$ Its structured, reliable and well-validated interview can help diagnose depressive disorders and suicidality more often than clinical assessment alone. ${ }^{[56]}$ Although CAMS has predominantly focused on outpatient treatment, there is merit in employing it in a variety of clinical settings as it can be tailored to other treatment

Published by Sciedu Press modalities.

Numerous books and journal articles are available for those wanting to learn more about CAMS. David Jobes' book Managing Suicidal Risk: A Collaborative Approach outlines this approach to working with suicidal clients. ${ }^{[38]}$ Implementation efforts have commenced in Canada and have led to CAMS training and adherence for nurses and therapists working with the suicidal population. In February 2015, a self-paced online training program, "Managing Suicide Risk Collaboratively: The CAMS Framework," was introduced and is currently being used in the U.S., Canada, Europe, Australia and Asia to improve competency, confidence and practice in suicide risk assessment, management and treatment. ${ }^{[57]}$

Rosemarie Rizzo Parse is an inspirational frontrunner who set out to enhance the nursing profession through theory, research, education and practice. Her distinguished HumanBecoming Theory focuses on the client's quality of life and the principles of human dignity. She has conducted and published multiple qualitative research studies about lived experiences of health and quality of life. This together with the CAMS framework, engrosses the suicidal patient differently than traditional modalities, and in so doing creates a distinct treatment path. This trajectory is primarily designed to enhance the therapeutic relationship between client and clinician.

This paper set out to briefly discuss the scope of the suicide problem. It reflected on the potential success of the CAMS conceptual framework coupled with Parse's HumanBecoming Theory for guiding suicide assessment and providing treatment. It suggests that Parse's Human Becoming theory with CAMS may warrant development and study, thus closing the theory-practice gap that currently exists in the care of the suicidal patient. Further, dedicated research is needed to understand more fully the impact of CAMS and nursing theory on the suicidal client. Nursing research and dissemination of knowledge needs to be improved in order for capacity building to occur.

\section{ACKNOWLEDGEMENTS}

The author would like to thank her colleagues at the Bridge to Recovery Program (St. Joes Healthcare Hamilton). These nurses, social workers, recreation and occupational therapists and peer support workers, provide therapy to suicidal patients on a daily basis. They tread where angels fear to go. Thank you for saving so many lives. In memory of Matt Sandig who took his life.

\section{Conflicts of Interest Disclosure}

The authors declare that there is no conflict of interest. 


\section{REFERENCES}

[1] Clarke DE, Colantonio A, Rhodes AE, et al. Pathways to suicidality across ethnic groups in Canadian adults: The possible role of social stress. Psychol Med. 2007 Nov 2; 38(3): 419-431.

[2] McCall C. Class, ethnicity, and social inequality. Quebec: McGillQueen's Press, c1990. 297 p.

[3] Welch SS. A review of the literature on the epidemiology of parasuicide in the general population. Psychiat Serv. 2001 Mar; 52(3): 36875. PMid:11239107. http://dx.doi.org/10.1176/appi.ps.5 2.3.368

[4] Goldner EM. Sharing the learning - The health transition fund Mental health, synthesis series [Internet]. Toronto (ON): Health Canada, 2002 [updated 2013 June 24; cited 2015 June 20]. Available from: http://www.hc-sc.gc.ca/hcs-sss/alt_formats/h pb-dgps/pdf/pubs/2002-htf-fass-integr/2002-htf-fas s-integr-eng.pdf

[5] Parliament of Canada. Mental health, mental illness and addiction: Overview of Policies and Programs in Canada, report 1. Journals of the Senate; c2004. Available from: http://www.parl.gc.ca

[6] LaLonde M. A new perspective on the health of Canadians: A working document [Internet]. Ottawa: Government of Canada; c1974. 77 p. Available from: http://www.phac-aspc.gc.ca/ph-sp/pdf/ perspect-eng.pdf

[7] Leenaars AA. Suicide prevention in Canada: A history of a community approach. Can J Commun Ment Health. 2000 Fall; 19(2): $57-$ 73. PMid:11381738. http://dx.doi.org/10.7870/cjcmh-200 $0-0015$

[8] Public Health Agency of Canada. Suicide-related research in Canada: A descriptive overview; c2005. Available from: http://www.phac-aspc.gc.ca/publicat/mh-sm/suicid e-research/b-eng.php\#1a

[9] Canadian Association for Suicide Prevention. The CASP blueprint for a Canadian national suicide prevention strategy [Internet]. Waterloo (ON): 2004 [updated 2014 May 28; cited 2015 June 17]. Available from: http://www.suicideprevention.ca/

[10] Health Canada. A report on mental illnesses in Canada. Ottawa (ON): Health Editorial Board, 2002 [cited 2015 June 24]. Available from: http://www.phac-aspc.gc.ca/publicat/miic-mmac/ app_b-eng.php

[11] Buchanan DR. An ethic for health promotion: Rethinking the sources of human well-being. New York: Oxford University Press; 2000. 214 p.

[12] Ramsay RF, Cooke MA, Lang WA. Alberta's suicide prevention training programs: A retrospective comparison with Rothman's developmental research model. Suicide Life-Threat. 1990 Dec; 20(4): 335-351.

[13] Tourangeau A. A theoretical model of the determinants of mortality. Adv Nurs Sci. 2005 Jan-Mar; 28(1): 58-69. PMid:15718939. http://dx.doi.org/10.1097/00012272-200501000-00007

[14] Kupperschmidt BR. Addressing multigenerational conflict: Mutual respect and carefronting as strategy. Online J Issues Nurs. 2006 May; 11(2): 4 .

[15] Jones KA. Developing the therapeutic use of self in the health care professional through autoethnography: Working with the borderline personality disorder population. Int J Qual Methods. 2012 Dec; 11(5): 573-584.

[16] Meleis A. Theoretical nursing: Development and process. Philadelphia: JB Lippincott; c2007. 672 p.

[17] Newman M, Sime M, Corcoran-Perry S. The focus of the discipline of nursing. Adv Nurs Sci. 1991 Sep; 14(1): 1-6.

[18] Donley SR. Challenges for nursing in the 21st century. Nurs Econ. 2005 Nov-Dec; 23(6): 312-318. PMid:16459903.
[19] Pryjmachuk S. A nursing perspective on the interrelationships between theory, research and practice. J Adv Nurs. 1996 Apr; 23(4): 679-84. PMid:8675883. http://dx.doi.org/10.1111/j $.1365-2648.1996 . t b 00037 . x$

[20] Cody WK, Mitchell GJ. Nursing knowledge and human science revisited: Practical and political considerations. Nurs Sci Q. 2002 Jan; 15(1): 4-13. PMid:11873471. http://dx.doi.org/10.1177/089 43180222108705

[21] Whelton JB. Nursing as a practical science: Some insight from classical Aristotelian science. Nurs Philos. 2001 Dec; 1(1): 57-63.

[22] Johns C. Becoming a reflective practitioner. Oxford: Blackwell Science; c2000. 344 p.

[23] Pompili M. Exploring the phenomenology of suicide. Suicide LifeThreat. 2010 Jun; 40(3): 234-44. PMid:20560745. http://dx. doi . org/10.1521/suli.2010.40.3.234

[24] Slee N, Spinhoven P, Garnefski N, et al. Emotion regulation as mediator of treatment outcome in therapy for deliberate self-harm. Clin Psychol Psychot. 2008 Jul-Aug; 15(4): 205-16. PMid:19115441. http://dx.doi.org/10.1002/cpp. 577

[25] May V. Attitudes to patients who present with suicidal behaviour. Emerg Nurse. 2011 July; 9(4): 26-32.

[26] Soukas J, Lonnqvist J. Work stress has negative effects on the attitudes of emergency personnel towards patients who attempt suicide. Acta Psychiat Scand. 1989 May; 79(5): 474-80. PMid:2750548. ht tp://dx.doi.org/10.1111/j.1600-0447.1989.tb10290.x

[27] Rhodes S. Commentary on John Cutcliffe: A historical overview of psychiatric/mental health nursing education in the United Kingdom: Going around in circles or on the straight and narrow? Nurs Educ Today. 2003 July; 23(5): 347-349. http://dx.doi.org/10. 1016 /S0260-6917(03) 00030-3

[28] Valente S. Nurses' psychosocial barriers to suicide risk management. Nurs Res Pract. 2011 Dec 24; Article ID 650765. http: //dx.doi.org/10.1155/2011/650765

[29] Simon RI. Assessing and managing suicide risk: Guidelines for clinically based risk management. Washington, DC: American Psychiatric Publishing; c2004. 256 p.

[30] Sun F, Lon A, Boore J, et al. A theory for the nursing care of patients at risk for suicide. J Adv Nurs. 2006 Mar; 53(6): 680-90. PMid:16553676. http://dx.doi.org/10.1111/j.1365-2648. 2006.03774.x

[31] Malone KM, Szanto K, Corbitt EM, et al. Clinical assessment versus research methods in the assessment of suicidal behaviour. AM J Psychiat. 1995 Nov; 152: 1601-1607. PMid:7485622. http: //dx.doi.org/10.1176/ajp.152.11.1601

[32] Lizardi D, Stanley B. Treatment engagement: A neglected aspect in the psychiatric care of suicidal patients. Psychiat Serv. 2010 Dec; 6(12): 1183-1191.

[33] Monti K, Cedereke M, Ojehagen A. Treatment attendance and suicidal behaviour 1 month and 3 months after a suicide attempt: A comparison between two samples. Arch Suicide Res. 2003 Nov; 7(2): 167-174. http://dx.doi.org/10.1080/13811110301581

[34] Comtois KA, Linehan MM. Psychosocial treatments of suicidal behaviors: A practice friendly review. J Clin Psychol. 2006 Dec; 62(2): 161-170. PMid:16342292. http://dx.doi.org/10.1002/jclp. 20220

[35] Marshall E, York J, Magruder K, et al. Implementation of online suicide-specific training for VA providers. Acad Psychiatry. 2014 Oct; 38(5): 566-74. PMid:24563240.

[36] Jobes DA, Lento R, Brazaitis K. An evidence-based clinical approach to suicide prevention in the department of defense: The collaborative assessment and management of suicidality (CAMS). Mil Psychol. 2012 Sept; 42(6): 604-623. 
[37] Jobes DA. The collaborative assessment and management of suicidality (CAMS): An evolving evidence-based clinical approach to suicidal risk. Suicide Life-Threat. 2012 Dec; 42(6): 640-653. PMid:22971238. http://dx.doi.org/10.1111/j.1943-278X. 2012.00119.x

[38] Jobes DA. Managing suicidal risk: A collaborative approach. New York: Guilford Press; c2006. 222 p.

[39] Comtois KA, Jobes DA, O'Connor SS, et al. Collaborative assessment and management of suicidality (CAMS): Feasibility trial for next-day appointment services. Depress Anxiety. 2011 Nov; 28(11): 963-972. PMid:21948348. http://dx.doi.org/10.1002/da. 20 895

[40] Ellis TE. Collaboration and a self-help orientation in therapy with suicidal clients. J Contemp Psychother. 2004 Spring; 34(1): 41-57. ht tp://dx.doi.org/10.1023/B: JOCP.0000010912.99125.6a

[41] Johnson LL, O'Connor SS, Kaminer B, et al. Suicide-focused group therapy for veterans. Mil Behav Health. 2014 Nov; 2(4): 327-336.

[42] Jobes DA, Comtois K, Brenner L, et al. Clinical trial feasibility studies of the collaborative assessment and management of suicidality (CAMS). In: R. C. O'Connor, S. Platt, and J. Gordon (Eds.). UK: Wiley-Blackwell; International handbook of suicide prevention: Research, Policy, \& Practice. C2011. 383 p.

[43] Crowley KJ, Arnkoff DB, Glass CR, et al. Collaborative assessment and management of suicidality (CAMS): Adherence to a flexible clinical framework. Los Angeles: American Association of Suicidology; c2014. 2 p.

[44] Nielsen AC, Alberdi F, Rosenbaum B. Collaborative assessment and management of suicidality method shows effect. Dan Med Bull. 2011Aug; 58(8): A4300. PMid:21827722.

[45] Conrad AK, Jacob AM, Jobes DA, et al. A psychometric investigation of the suicide status form II with a psychiatric inpatient sample. Suicide Life-Threat. 2009 June; 39(3): 307-320.

[46] Parse RR. Major paradigms, theories and critiques. Philadelphia: Saunders; c1987. 214 p.

[47] Parse RR. The human becoming school of thought: A perspective for nurses and other health professionals. Thousand Oaks: Sage; c1998. $130 \mathrm{p}$.
[48] Kreitzer M. Integrative Nursing: Application of Principles Across Clinical Settings. Rambam Maimonides Med. J. 2015 Apr; 6(2): e0016. PMid:25973268. http://dx.doi.org/10.5041/RMMJ . 10200

[49] Parse RR. Man-living health: A theory of nursing. New York: John Wiley; c1981. $202 \mathrm{p}$.

[50] Jonkus D. Stages of Husserl's Philosophy and Intention of Phenomenology. Horizon. 2014; 3(1): 93-11.

[51] World Health Organization. World Report on Violence and Health. WHO: Geneva; c2002. 360 p.

[52] Starks H, Brown Trinidad S. Choose your method: A comparison of phenomenology, discourse analysis, and grounded theory. Qual Health Res. 2007 Dec; 17(10): 1372-1380. PMid:18000076. http://dx.doi.org/10.1177/1049732307307031

[53] Ellis TE, Green KL, Allen JG, et al. Collaborative assessment and management of suicidality in an inpatient setting: Results of a pilot study. Psychother. 2012 Mar; 49(1): 72-80. PMid:22369081. http://dx.doi.org/10.1037/a0026746

[54] Chisolm S. An important message from Canadian Association for suicide prevention. Collateral Damage, Those Left Behind By Suicide. 2009 May 2 [updated 2012 Jan 12; cited 2015 June 15] Available from: http://leftbehindbysuicide.org/uncate gorized/an-important-message-from-canadian-associa tion-for-suicide-prevention

[55] Westra HA, Dozois DJ. In: H. In Arkowitz, H.A. Westra, W.R. Miller, S. Rollnick (Eds), Motivational interviewing in the treatment of psychological problems. New York: Guilford Press; c2008. 26-56 p.

[56] Kim YS, Cheon KA, Kim BN, et al. The reliability and validity of Kiddie-Schedule for affective disorders and schizophrenia - present and lifetime version - Korean version. Yonsei Med J. 2004 Feb; 45(1): 81-9.

[57] Jobes DA. Reflections on suicide among soldiers. Psychiatr. 2013 Dec; 76(2): 126-131. PMid:23631543. http://dx.doi.org/10. 1521/psyc.2013.76.2.126 